ing $\mathrm{pH}$. At very high $\mathrm{pH}$ values $(\mathrm{pH}=13)$, the corrosion rate of the phosphate glass surface was so rapid that the silane could not form a stable bond with the surface and no APS could be detected by $x$-ray photoelectron spectroscopy (XPS).

The researchers also determined that the concentration of silane on the surface of silicate glasses increases with increasing solution concentration until a critical value is reached where the surface concentration then becomes constant, independent of solution concentration. The adsorbed concentration of silane on the surface of the phosphate glass also increased with increasing solution concentration.

In contrast though, after forming a monolayer, the concentration of silane on the surface then begins to rise rapidly with increasing solution concentration, due to the formation of multilayers. Additionally, said Barnes, the shape of the high-resolution spectra peak by XPS changes with solution concentration. This peak can provide information concerning the state of the nitrogen in the adsorbed silane layer, showing both a free amine $\left(-\mathrm{NH}_{2}\right)$ and a protonated amine $\left(-\mathrm{NH}_{3}^{+}\right)$at different binding energies. At low concentrations, the nitrogen is almost entirely in the free state, Barnes said, suggesting that APS is adsorbing to the surface through the hydrolyzed alkoxy group (the silane end). As multilayers begin to form, the protonated amine concentration begins to increase.

Barnes said that very little literature is available on the surface of phosphate glasses and even less on the factors effecting silane adsorption to phosphate glasses. She said that phosphate glasses are finding ever-increasing uses in both photonics and optics applications and the ability to couple the glass with other materials to form composite or hybrid structures is important in both present and future applications. Understanding how to effectively adsorb a coupling agent to the surface is the first step to expanding the potential applications of multicomponent phosphate glasses, she said.

"Applications to join two phosphate glasses, phosphate glass and polymers, or phosphate glass and other organic chemicals are just beginning," said Barnes. "With a silane coating, these glasses can be used as hybrids rather than standalone materials. We can connect and combine them with dissimilar materials."

\section{Various Avenues Taken in Search for Diamonds}

Geological studies are exploring evidence from Venus to several hundred kilometers under the Earth's surface to determine ways to locate diamonds.

Some of southern Africa's most prof- itable diamond mines are located near areas where the earth is exceptionally stable and cool up to $250 \mathrm{~km}$ below the surface, according to Matt Fouch, assistant professor of geological sciences at Arizona State University; David James and John VanDecar of the Department of Terrestrial Magnetism, Carnegie Institution of Washington; and Suzan van der Lee of the Institute of Geophysics, Zürich, Switzerland. Geologists think diamonds develop up to several hundred kilometers deep within ancient cratons - such as over 3 billion years old-and are then driven straight up to the surface.

Fouch said, "Nearly all diamonds come from cratons, but not all cratons contain diamonds. So the question is, why do some cratons produce diamonds and others don't?"

By imaging the earth at depths of several hundred kilometers beneath the crust, Fouch and his colleagues looked at the source of diamonds. The seismic team created three-dimensional images of deep layers of the earth by using an array of 82 seismometers. As reported by David James and co-workers in the July 1 issue of Geophysical Research Letters, the seismometers, placed at roughly $100-\mathrm{km}$ intervals across South Africa, Zimbabwe, and Botswana, recorded data from more than 200 earthquakes occurring over a two-year period, mainly from the Himalayan and Andean mountain ranges. The team used seismic tomography to produce the images.

Fouch said, "The seismic waves from each earthquake bounce off of different layers of the earth and illuminate different internal features."

The researchers found that in diamondproducing areas, the mantle is "seismically fast," meaning that it propagates earthquake vibrations quickly because the mantle rock may be cooler or chemically different from the surrounding areas.

Fouch said that nearly all diamond sources are found in regions of cratons with thick underlying lithosphere-the tectonic plate. Seismological techniques are some of the highest-resolution methods used to determine the thickness of the plate, as well as the strength of the variations in elastic properties. Therefore, he said, making precise measurements of relative seismic velocities of the lithospheric plate provides important constraints on the relationship between the lithosphere and diamondiferous regions. One of these regions, the research team reported, is beneath the Kaapvaal craton in South Africa and one is beneath the Zimbabwe craton.

Fouch said, "Most of the gem-quality diamond mines in southern Africa lie very close to these regions."
Looking to Venus for clues, Richard Ghail, a research associate at the Imperial College in London, believes the sister planet is key to understanding what early Earth was like during the Archaean and early Proterozoic time periods when precious resources were formed.

While modern Venus is in a quiet state most of the time, it enters into short periods of intense volcanic activity where the old surface of Venus is destroyed and a new one is created. In its early history, Earth worked in a similar way to modern Venus.

"By understanding the 'early Earth,' we can predict where to find precious resources-such as platinum and diamonds," said Ghail.

In preparation for his presentation at the Earth Systems Processes Conference on June 27, in Edinburgh, Scotland, Ghail said that "from the evidence from Venus, the early Earth did not have modern plate tectonics, but did have something that looked similar to it."

The evidence for this derives from the evidence of higher mantle temperatures $\left(200^{\circ} \mathrm{C}\right.$ or higher) and higher heat flow in the Archaean Earth, which prevented subduction, and hence modern-style plate tectonics, from taking place, by causing the lithosphere (the cool, rigid outermost layer of the Earth) to be thin and buoyant. Venus is in a similar state today because it has a high surface temperature $\left(450^{\circ} \mathrm{C}\right)$ that also results in a thin buoyant lithosphere. Research over the last 10 years has shown that Venus operates in two modes, Ghail said. For the most part, Venus exists in a state of relative quiet in which platelike movements occur (creating rifts, mountain belts, and strikeslip faults, all with associated volcanism) but then, every 500-1000 million years, there is a short period (100 million years or less) of intense volcanism that resurfaces most of the planet. The reason for this strange behavior, Ghail said, is that without subduction, neither modern Venus nor the early Earth could cool efficiently enough to prevent their upper mantle from heating up and eventually melting.

The release of all the melt to the surface in a short time cools the mantle down and resets the clock. Eventually, Earth was sufficiently cooled by one of these episodes that plate tectonics could start. So, according to the research, Venus provides an analogue of the types of tectonic settings that existed on the Archaean Earth, in which many precious resources were formed.

The conference was sponsored by the Geological Society of America and the Geological Society of London. 